\title{
Desempenho, características de carcaça e qualidade da carne de bovinos superprecoces das raças Canchim, Nelore e seus mestiços
}

\author{
Gabriel Antonio Garrido Rubiano ${ }^{1}$, Mário De Beni Arrigoni², Cyntia Ludovico Martins² ${ }^{2}$ Érico \\ Rodrigues $^{3}$, Heraldo Cesar Gonçalves ${ }^{4}$, Camila Nogueira Angerami ${ }^{3}$ \\ 1 Universidad de Ciencias Aplicadas y Ambientales - UDCA - CII: 222, n 54-37, Tel: (57 1) 6684700, Bogotá, Colômbia. \\ 2 DMNA, FMVZ/UNESP/Botucatu. \\ ${ }^{3}$ Pós-Graduando da FMVZ/Unesp/Botucatu. \\ ${ }^{4}$ DPEA FMVZ/UNESP/Botucatu.
}

RESUMO - Oitenta e seis machos jovens, não-castrados, divididos em quatro grupos raciais - Nelore ( $\mathrm{n}=20$ ), Canchim $(n=17), 1 / 2$ Canchim $\times$ Nelore $(C N)(n=25)$ e $3 / 4$ Canchim $\times$ Nelore (TQ) $(n=24)-$ foram pesados a cada 28 dias para avaliação de ganho de peso (kg/dia), ingestão de matéria seca ( $\mathrm{kg} /$ dia) e conversão alimentar. Ao atingirem peso de abate médio de $450 \mathrm{~kg}$ e espessura de gordura subcutânea superior a $4 \mathrm{~mm}$, os animais foram abatidos para avaliação do peso e do rendimento de carcaça e de cortes comerciais do traseiro, área de olho-de-lombo, espessura de gordura subcutânea (mm), marmorização, força de cisalhamento, extrato etéreo (\%) e perdas por cocção. O grupo Nelore apresentou-se adequado ao sistema de produção proposto, revelando desempenho similar ao dos animais CN quanto ao ganho de peso (1,18 e 1,29 kg para Nelore e CN, respectivamente) e conversão alimentar (6,90 e 7,04 para Nelore e CN, respectivamente). A ingestão de matéria seca (kg/dia) diferiu entre os grupos raciais (11,82; 9,39; 8,90 e 8,31 para Canchim, TQ, CN e Nelore, respectivamente). O peso da carcaça $(\mathrm{kg})$ dos Canchim $(291,14)$ foi maior e diferiu dos outros grupos $(250,74 ;$; 246,64 e 244,18 para TQ, CN e Nelore, respectivamente). Apesar de o rendimento de carcaça ter sido maior no grupo Nelore (58,75\%), os animais desse grupo apresentaram menor rendimento de cortes nobres que de traseiro, com diferença para o contrafilé $(10,22 ; 11,55 ; 11,64$ e 11,18 para Nelore, Canchim, TQ e CN, respectivamente). Os valores de força de cisalhamento comprovam que o abate de animais jovens garante carne macia, independentemente do grupo genético estudado.

Palavras-chave: área de olho-de-lombo, confinamento, conversão alimentar, espessura de gordura subcutânea, maciez

\section{Performance, carcass traits and meat quality of young Canchim, Nellore and crossbread bulls}

\begin{abstract}
Eighty six young bulls were used, divided into four genetic groups: Nellore ( $\mathrm{n}=20$ ), Canchim ( $\mathrm{n}=17)$, $1 / 2$ Canchim $\times$ Nellore $(\mathrm{NC})(\mathrm{n}=25)$ and $3 / 4$ Canchim $\times$ Nellore (TQ) $(n=24)$. The animals were weighed every 28 days to evaluate the average daily gain (kg/day), dry matter intake (kg/day) and feed conversion. When the animals reached slaughter weight $(450 \mathrm{~kg})$ and fat thickness greater than $4 \mathrm{~mm}$, were slaughtered to evaluate the rib eye area $\left(\mathrm{cm}^{2}\right)$, subcutaneous fat thickness (mm), marbling, shear force, ether extract (\%) and total cooking losses. The Nellore group fitted correctly into the proposed system, showing similar performance when compared to the CN group (1.18 and $1.29 \mathrm{~kg} / \mathrm{day}$ for Nellore and $\mathrm{CN}$, respectively) and feed conversion (6.90 and 7.04 for Nellore and CN, respectively). The dry matter intake (kg/day) differed among all groups (11.82, 9.39, 8.90 and 8.31 for Canchim, TQ, CN and Nellore, respectively). The carcass weight (kg) was higher in the Canchim group (291.14) than the other groups (250.74, 246.64 and 244.18 for TQ, CN and Nellore respectively). Although the carcass dressing percentage of the Nellore group (58.75\%) was the highest, this group had the lowest yield of commercial cuts in the hindquarter especially for the sirloin (10.22, 11.55, 11.64 and 11.18\% for Nellore, Canchim, TQ and CN, respectively). The shear force values indicated that the slaughter of young animals can assure tender beef regardless of the genetic group.
\end{abstract}

Key Words: feedlot, feed to gain ratio, rib eye area, subcutaneous fat thickness, tenderness

\section{Introdução}

Até o início dos anos 90, praticamente toda a carne de bovinos machos que chegava ao consumidor era originária de novilhos de 3 a 5 anos de idade, e era um produto de baixa qualidade. Silveira (1995) demonstrou que a redução na idade de abate, aliada ao potencial genético dos animais, tem sido uma importante 
alternativa para produzir carne com eficiência e qualidade.

No início da década de 90, a Faculdade de Medicina Veterinária e Zootecnia da UNESP - Botucatu iniciou estudos sobre a produção intensiva de carne visando, tanto benefícios sociais quanto melhor retorno financeiro para o produtor. Esses estudos visavam também aumentar a oferta constante de carne de melhor qualidade, assegurando maior valorização do produto brasileiro, tanto dentro quanto fora do País.

O sistema de produção de bovinos superprecoces animais que, após a desmama, são terminados em regime de confinamento e abatidos com idade de até 15 meses, com peso vivo mínimo de $450 \mathrm{~kg}$ e cobertura de gordura subcutânea na carcaça superior a 4 mm que, juntamente com a idade jovem dos mesmos, garante melhor qualidade da carne (Silveira, 1995) - explora a eficiência biológica (ganho de peso vivo em relação ao consumo de energia) e concilia os efeitos de manipulação de fatores genéticos e ambientais nas transformações dos tecidos durante a fase acelerada do crescimento.

Aliado à redução da idade de abate, o cruzamento tem sido fundamental na intensificação do sistema de produção de bovinos de corte. Até o início dos anos 90, o genótipo utilizado na produção pecuária dependia muito da preferência do pecuarista. No entanto, com a redução da lucratividade da pecuária de corte e a concorrência dos demais países produtores de carne bovina, o produtor passou a buscar genótipos mais adequados ao seu sistema de produção, ou seja, aqueles mais eficientes em converter alimento consumido em ganho de peso e que atendessem a demanda do mercado, principalmente em qualidade de carcaça e de carne.

Desta forma, objetivou-se com este trabalho avaliar o desempenho, as características de carcaça, o rendimento de cortes e a qualidade da carne de animais Canchim, Nelore, $1 / 2$ Canchim $\times$ Nelore $(C N)$ e 3/4 Canchim $\times$ Nelore (TQ) no modelo biológico superprecoce.

\section{Material e Métodos}

O experimento foi conduzido no confinamento experimental do Departamento de Melhoramento e Nutrição Animal da FMVZ, Unesp, Campus de Botucatu com 86 bezerros machos, não-castrados: 20 Nelore, 25 $1 / 2$ Nelore $\times$ Canchim $(\mathrm{CN}), 24$ 3/4 Canchim $\times$ Nelore (TQ) e 17 Canchim. Os animais utilizados foram desmamados com 7 meses de idade, peso vivo médio de $276 \mathrm{~kg}$, criados em sistema creep feeding, provenientes de parcerias. Os animais iniciaram o período de confinamento com pesos médios de 251 kg (Nelore), 321 kg (Canchim), 279 kg (TQ) e $262 \mathrm{~kg}$ (CN) e foram mantidos em baias de concreto, com lotação de cinco animais por baia ( $5 \mathrm{~m}^{2}$ por animal e 1,20 m linear de cocho por animal), de modo que cada uma delas continha apenas animais do mesmo grupo genético. As baias eram cobertas e com boa circulação de ar, protegendo os animais e o alimento do sol e da chuva.

Após a chegada ao local do experimento, os animais tiveram um período de duas semanas de adaptação à dieta e às instalações. Depois desse período, todos os animais foram pesados, após jejum alimentar de 16 horas, e iniciou-se o experimento. Os animais receberam a mesma ração, à vontade, duas vezes ao dia (manhã e tarde) com água constante nos bebedouros automáticos. A dieta foi formulada para atender às exigências em crescimento/ terminação para ganhos de 1,3 a 1,6 kg/dia, de acordo com as recomendações do NRC (1996), utilizando o sistema Cornell Net Carbohydrate and Protein System 5.0.26 (Tabela 1).

A dieta foi submetida a ajustes diários da quantidade fornecida, com base no escore de cocho antes de cada refeição (8 e 12 h). O escore de cocho foi determinado por meio da avaliação visual da quantidade de sobras deixada pelos animais no cocho antes de cada fornecimento de alimento, trabalhando com sobras de $5 \%$. Os animais foram pesados a cada 28 dias, após jejum alimentar de 16 horas, para o monitoramento do ganho diário de peso vivo e ajuste do consumo da dieta conforme o peso vivo.

Uma vez atingido peso de abate acima de $450 \mathrm{~kg}$ e gordura de acabamento maior que $4 \mathrm{~mm}$, monitorada por meio de ultrassom, os animais foram abatidos em frigorífico

Tabela 1 - Composição em ingredientes e nutricional da dieta

\begin{tabular}{|c|c|}
\hline Ingrediente & $\% \mathrm{MS}$ \\
\hline Feno de coast cross & 5,25 \\
\hline Silagem de milho & 28,25 \\
\hline Silagem de grãos úmidos de milho & 55,5 \\
\hline Concentrado proteico $^{1}$ & 11 \\
\hline \multicolumn{2}{|l|}{ Nutriente } \\
\hline$\% \mathrm{MS}$ & 58,21 \\
\hline Energia metabolizável (Mcal/kg MS) & 2,60 \\
\hline Proteína bruta (\%) & 17,27 \\
\hline Fibra em detergente neutro (\%) & 25,63 \\
\hline Fibra em detergente ácido (\%) & 15,70 \\
\hline Proteína degradável no rúmen (\%PB) & 74 \\
\hline FDN efetiva & 20 \\
\hline Extrato etéreo total (\%) & 3,49 \\
\hline Matéria mineral (\%) & 3,90 \\
\hline
\end{tabular}


comercial. As carcaças quentes foram pesadas para a obtenção dos dados de rendimento de carcaça e, após a pesagem, foram resfriadas por 24 horas, para obtenção e pesagem dos principais cortes do quarto traseiro.

O músculo contrafilé (longissimus dorsi) foi retirado inteiro da meia-carcaça esquerda e congelado para ser posteriormente dividido em várias secções de $2,5 \mathrm{~cm}$ de espessura, permitindo, dessa forma, a utilização de amostras independentes para cada teste laboratorial realizado. Depois de seccionadas, as amostras foram retiradas do freezer e deixadas no refrigerador $\left(18^{\circ} \mathrm{C}\right)$ por 24 horas para serem descongeladas e utilizadas nas diferentes análises laboratoriais. Amostras também foram embaladas a vácuo e deixadas maturar por 7 dias a $4{ }^{\circ} \mathrm{C}$ para posterior análise de força de cisalhamento e perdas por cocção. Imediatamente após o descongelamento das amostras, foi medida a área de olho-de-lombo, utilizando-se uma matriz plástica formada por quadrados com uma área de $1 \mathrm{~cm}^{2}$ cada, obtendo-se a área total a partir da contagem dos quadrados que se encontravam na superfície do músculo. A espessura de gordura subcutânea foi obtida traçando-se uma linha imaginária correspondente ao maior diâmetro da superfície exposta do longissimus dorsi, seguido da marcação de outra linha cortando a primeira a 3/4 de distância de sua extremidade cranial, medindo-a com auxílio de paquímetro.

O grau de marmorização do músculo longissimus dorsi foi avaliado por meio da comparação visual da amostra com tabela gráfica com cinco diferentes graus de marmorização: 1) praticamente ausência de marmoreio; 2) poucos traços de marmoreio; 3) pequeno a moderado marmoreio; 4) marmoreio moderado a ligeiramente abundante; 5) marmoreio abundante.

Para determinação da força de cisalhamento, as amostras do músculo longissimus dorsi foram colocadas em bandejas providas de grelhas, pesadas sem e com as amostras, sequencialmente. Um termoacoplador foi inserido no centro geométrico de cada amostra e o conjunto composto pela bandeja, grelha e levada a um forno elétrico pré-aquecido a $200{ }^{\circ} \mathrm{C}$, por 20 minutos, aproximadamente. A temperatura da amostra foi monitorada constantemente até atingir $40{ }^{\circ} \mathrm{C}$, quando então as amostras foram viradas, e retiradas do forno quando atingiram temperatura interna de $71^{\circ} \mathrm{C}$. Uma vez retiradas do forno, as amostras foram pesadas, com a grelha e a bandeja, de forma a se obterem as perdas por evaporação. Posteriormente, as amostras foram mantidas a temperatura ambiente e, a seguir, colocadas em refrigerador a $4{ }^{\circ} \mathrm{C}$ por 24 horas.

Após o período de 24 horas de resfriamento, as amostras do músculo longissimus dorsi foram retiradas do refrigerador, das quais foram obtidos 9 cilindros de diâmetro aproximado de $1,27 \mathrm{~cm}$, um retirado do centro geométrico da amostra e os oito demais ao longo do restante da amostra. Os cilindros foram levados ao aparelho Warner Bratzler Shear Machine, onde foram tomadas as medidas de força de cisalhamento.

Para se obter o valor de extrato etéreo, as amostras foram moídas em um multiprocessador. Foram retirados e pesadas, aproximadamente, 3 gramas de cada amostra, que foram adicionados em erlenmeyer de $250 \mathrm{~mL}$. Em seguida, foram adicionados 10,0 $\mathrm{mL}$ de clorofórmio, 20,0 mL de metanol e 8,0 mL de água destilada. O material foi dissolvido totalmente, com auxílio de bastão de vidro, para maior contato dos reagentes com as amostras. Posteriormente, foram levados a uma mesa agitadora por 30 minutos, em velocidade média. Após agitação, adicionaram-se mais 10,0 mL de clorofórmio e 10,0 mL de solução de sulfato de sódio a $1,5 \%$, agitando-se por mais dois minutos, vigorosamente. Posteriormente, as amostras foram transferidas para dois tubos plásticos $(50,0 \mathrm{~mL})$ para serem centrifugadas por dois minutos a $3300 \mathrm{rpm}(1000 \mathrm{X}$ g) a $25^{\circ} \mathrm{C}$. Foi descartado o sobrenadante, sendo o precipitado filtrado e acondicionado em provetas de $25,0 \mathrm{~mL}$, onde foi determinado o volume de filtrado. Um volume de 5,0 $\mathrm{mL}$ do filtrado foi coletado e transferido para um becker previamente pesado, que foi levado à estufa para evaporação do clorofórmio. Após este procedimento, os beckers foram secos em estufa e resfriados em dessecador. Foram então pesados e os resultados de extrato etéreo foram obtidos pela diferença entre o peso inicial do becker (antes de ser transferido o filtrado para o mesmo) e o peso final (depois que o clorofórmio das amostras evaporou) (Bligh \& Dyer, 1959).

O delineamento experimental utilizado foi o inteiramente casualizado, com 4 tratamentos e as repetições dentro de cada tratamento correspondendo ao número de animais usados de cada grupo racial. Para avaliação da qualidade de carne, foram utilizados 40 animais e, para desempenho e características de carcaça, foram utilizados 86 animais. Os dados foram analisados utilizando o sistema de análises estatísticas e genéticas SAEG 9.0., e para a comparação entre as médias e o teste Tukey $(\mathrm{p}<0,05)$ foi adotado.

\section{Resultados e Discussão}

O peso vivo inicial foi maior $(\mathrm{p}<0,05)$ nos animais Canchim (321,2 kg) que nos outros grupos raciais (Tabela 2), que não apresentaram diferenças entre si ( $p>0,05)$, o que pode estar relacionado à origem dos animais puros Canchim, oriundos de rebanhos de produtores de animais elite, 
sendo os animais experimentais portadores de potencial genético para crescimento, mesmo sendo representantes do descarte das fazendas. Provavelmente, os animais puros Canchim não sofreram os efeitos do estresse do início do confinamento por estarem adaptados a manejo e dietas de sistemas intensivos.

Os animais Canchim, considerados de maior porte, apresentaram os maiores pesos ao abate e diferiram $(p<0,05)$ dos outros grupos raciais (Tabela 2). Os mestiços não apresentaram diferenças entre si ( $\mathrm{p}>0,05)$ : os TQ tiveram maior peso final que os da raça Nelore e estes não diferiram dos CN. Isto evidenciou a influência do maior porte do grupo racial Canchim em relação ao tamanho dos outros animais, de modo que maior porcentagem de sangue Canchim originou animais de tamanho maior. Não houve, porém, diferença $(p>0,05)$ entre os dois cruzamentos TQ e CN (Tabela 2).

Animais de raças menores normalmente atingem o grau de acabamento em menor tempo. Neste trabalho, no entanto, os animais Nelore tiveram que permanecer mais uma semana no confinamento para chegar ao peso de abate, embora já tivessem atingido o acabamento requerido.

O maior consumo de matéria seca, em $\mathrm{kg} / \mathrm{dia}$, foi observado nos animais Canchim, seguidos pelos TQ, CN e por último pelos animais Nelore (Tabela 3) e todos diferiram entre si $(\mathrm{P}<0,05)$, refletindo no ganho de peso diário desses animais. Assim, os animais Canchim apresentaram o maior ganho de peso diário médio e não houve diferença em relação ao grupo TQ e ao grupo CN, mas sim em relação ao grupo Nelore. Os animais Nelore tiveram o mesmo GMD dos animais CN. Essas diferenças também podem ser explicadas pela influência dos portes das duas raças puras usadas no cruzamento,uma vez que a maior porcentagem de sangue Canchim apresentou maior consumo e melhor ganho de peso.

Os consumos diários de matéria seca pelos animais mestiços foram ligeiramente mais elevados (Tabela 2) que os encontrados por Euclides Filho et al. (2001), que reportaram 8,25 kg de matéria seca/dia em animais cruzados Canchim, Simental e Nelore. Costa et al. (2002) também encontraram resultados inferiores, que variaram de 6,90 a 6,95 kg de matéria seca/dia, sendo o peso de abate de $430 \mathrm{~kg}$ de peso vivo e acabamento de 3,91 mm de gordura subcutânea. Apesar de os animais Canchim puros apresentarem ingestão de matéria seca maior que a obtida nos demais grupos, quando comparadas as ingestões em relação ao peso vivo, estas não tiveram diferenças $(\mathrm{P}>0,05)$ (Tabela 2).

Tabela 2 - Desempenho e características de carcaça de bovinos jovens de diferentes grupos raciais avaliados no sistema superprecoce

\begin{tabular}{|c|c|c|c|c|c|}
\hline \multirow[t]{2}{*}{ Característica } & \multicolumn{5}{|c|}{ Grupo racial } \\
\hline & Canchim & TQ & $\mathrm{CN}$ & Nelore & CV (\%) \\
\hline Peso inicial (kg) & $321,18 \mathrm{a}$ & $270,37 b$ & $262,56 b$ & $251,40 b$ & 10,89 \\
\hline Peso final (kg) & $524,35 a$ & $457,83 b$ & $446,28 \mathrm{bc}$ & $423,10 c$ & 8,15 \\
\hline Ganho de peso total (kg) & $203,18 \mathrm{a}$ & $187,46 a b$ & $183,72 \mathrm{ab}$ & $171,70 \mathrm{~b}$ & 12,76 \\
\hline Ganho peso/ dia (kg) & $1,43 a$ & 1,32a & 1,29ab & $1,17 b$ & 12,79 \\
\hline IMS/dia (kg) & $11,82 \mathrm{a}$ & $9,39 b$ & $8,90 \mathrm{c}$ & $8,30 \mathrm{~d}$ & 5,28 \\
\hline Conversão alimentar & $8,27 \mathrm{a}$ & $7,11 \mathrm{~b}$ & $7,04 \mathrm{~b}$ & $6,90 \mathrm{~b}$ & 5,26 \\
\hline IMS \%peso vivo & 2,79 & 2,58 & 2,51 & 2,45 & \\
\hline Dias de confinamento & 142 & 142 & 142 & 149 & \\
\hline Peso da carcaça quente $(\mathrm{kg})$ & $291,14 \mathrm{a}$ & $250,74 b$ & $246,64 b$ & $244,18 b$ & 8,77 \\
\hline Rendimento da carcaça (\%) & $55,42 b$ & $54,77 b$ & $54,73 b$ & $58,75 a$ & 6,38 \\
\hline
\end{tabular}

IMS: ingestão de matéria seca.

Médias seguidas por letras distintas na mesma linha, diferem $(\mathrm{p}<0,05)$ entre si pelo teste Tukey.

Tabela 3 - Rendimento de cortes nobres do quarto traseiro de bovinos jovens de diferentes grupos raciais

\begin{tabular}{|c|c|c|c|c|c|}
\hline \multirow[t]{2}{*}{ Característica } & \multicolumn{5}{|c|}{ Grupo racial } \\
\hline & Canchim & TQ & $\mathrm{CN}$ & Nelore & CV (\%) \\
\hline Coxão mole (\%) & 11,39 & 11,39 & 11,55 & 11,70 & 5,82 \\
\hline Coxão duro (\%) & 6,21 & 6,25 & 6,17 & 6,26 & 8,40 \\
\hline Alcatra (\%) & 6,31 & 6,54 & 6,45 & 6,54 & 5,44 \\
\hline Patinho (\%) & 6,77 & 6,63 & 6,45 & 6,60 & 7,95 \\
\hline Picanha (\%) & 2,70 & 2,67 & 2,40 & 2,69 & 11,75 \\
\hline File mignon (\%) & 2,92 & 2,71 & 2,85 & 2,92 & 8,21 \\
\hline Contrafile (\%) & $11,55 \mathrm{a}$ & $11,63 a$ & $11,17 \mathrm{a}$ & $10,22 b$ & 5,32 \\
\hline Sebo (\%) & $1,37 \mathrm{~b}$ & $1,81 \mathrm{ab}$ & $1,57 b$ & $2,64 a$ & 44,18 \\
\hline Retalho (\%) & 1,24 & 1,17 & 1,17 & 0,83 & 42,74 \\
\hline
\end{tabular}

Médias seguidas por letras distintas na mesma linha, diferem $(\mathrm{p}<0,05)$ entre si pelo teste Tukey. 
A diferença nos valores de consumo de matéria seca em kg/dia e de conversão alimentar entre as raças Canchim e Nelore pode sugerir a possibilidade de que estas duas variáveis não são boas características para comparação entre animais de potencias diferentes, conforme relatado por Euclides Filho et al. (2001,2003).

Na conversão alimentar (Tabela 2), não houve diferença $(\mathrm{P}>0,05)$ entre os grupos TQ, CN e Nelore. A raça Canchim aporta maior capacidade de ingestão e a raça Nelore, conversão alimentar melhor. Segundo Euclides Filho et al. (2001, 2003), correlações entre consumo de matéria seca e ganho de peso podem não ser lineares entre os diversos grupos raciais e a conversão alimentar não seria capaz de considerar essas diferenças. De qualquer modo, seria esperado maior consumo para os animais com maior predominância de sangue Charolês, em razão de seu maior potencial produtivo e das maiores exigências nutricionais (NRC, 1996).

Euclides Filho et al. (2003) encontraram conversão alimentar $(7,90)$ ligeiramente inferior aos relatados para animais Canchim. Essa variação nos resultados de consumo e conversão alimentar é relativamente comum na literatura, uma vez que são vários os fatores que influenciam essa variável. Capelle et al. (2001), em revisão de trabalhos envolvendo essas duas variáveis, relataram valores médios de $9 \mathrm{~kg}$ de IMS/dia em animais Nelore, com um ganho de peso médio de $0,87 \mathrm{~kg} /$ dia e de 10,4 $\mathrm{kg}$ de IMS/dia para animais meio-sangue Europeu-Nelore, com ganhos médios de $1 \mathrm{~kg} /$ dia. Foram obtidos melhores resultados em relação a estas variáveis neste trabalho (Tabela 2) e esse fato foi influenciado pela idade dos animais, pelo seu alto valor genético, pelo tipo de manejo e pela dieta consumida.

Neste trabalho, os animais Nelore tiveram que permanecer uma semana a mais no confinamento, visto que no momento em que os outros animais estavam prontos para serem abatidos, pois já haviam atingido o peso e acabamento de gordura exigidos pelo frigorífico, os animais Nelore ainda estavam mais leves, mesmo tendo superado a espessura de gordura subcutânea de $4 \mathrm{~mm}$ exigida pelo frigorífico.

O peso de carcaça foi maior $(\mathrm{p}<0,05)$ para os animais Canchim, refletindo o peso vivo com que os animais foram abatidos (Tabela 2) e indicando que animais com composição racial predominante de animais de maior tamanho corporal necessitam de maior peso ao abate para obterem acabamento semelhante ao de animais com maior precocidade de deposição de gordura.

Mesmo havendo diferenças $(\mathrm{P}<0,05)$ nos pesos vivos finais entre os animais TQ e os Nelores, não foram registradas diferenças entre eles para o peso da carcaça (Tabela 2). Esse fato pode ser explicado pela influência da raça Nelore nos animais mestiços, uma vez que os animais de raças zebuínas apresentam melhor rendimento de carcaça em relação aos de raças taurinas.

Pacheco et al. (2005) encontraram em animais $5 / 8$ Nelore $\times 3 / 8$ Canchim, pesos de carcaça variando de 239,25 a $242,52 \mathrm{~kg}$, inferiores aos desta pesquisa (291,14 kg). Restle \& Vaz (2003) abateram animais F1 Nelore $\times$ Charolês com 2 anos de idade e verificaram pesos de carcaça de $247,7 \mathrm{~kg}$.

Em relação ao rendimento de carcaça, os animais Nelore apresentaram valor maior que o dos demais grupos avaliados (Tabela 2). Os valores obtidos neste trabalho foram maiores que os valores encontrados por De Faria (2004), que obteve valores de rendimento de carcaça de 57 e 57,35\% para animais Nelore e Nelore selecionados, respectivamente. Os valores obtidos neste estudo mostram maior rendimento de carcaça para os animais zebuínos (Tabela 2), concordando com Restle et al. (1999), que também mostraram maior rendimento de carcaça em genótipos zebuínos (52,7\%) em relação aos taurinos (51\%).

De modo geral, vários autores (Euclides Filho et al., 1997; Cruz et al, 2004) que estudaram o rendimento de carcaça comparativo de diferentes grupos genéticos descreveram que animais Nelore apresentam ossatura mais delgada, além do couro fino, portanto mais leves e com menor peso de cabeça.

Os animais mestiços não apresentaram diferenças significativas $(\mathrm{P}>0,05)$ entre si se considerados os parâmetros de desempenho e de carcaça, o que denota a habilidade de um sistema intensivo de produção de carne para padronizar as características de desempenho e de carcaça (Tabela 2) de animais de diferentes grupos raciais, tamanhos e taxas de crescimento e que, segundo Restle \& Vaz (2003), também é explicado pelo fato de animais jovens, em fase de crescimento apresentarem menores diferenças de ganho de peso e de composição de carcaça. Os resultados obtidos neste trabalho são semelhantes aos encontrados por Pacheco et. al (2005), que observaram rendimento de carcaça de 55,81\% para animais de mesma composição racial, e Igarasi et al. (2008a, b), que estudaram características de carcaça de bovinos tri cross no sistema superprecoce de produção alimentados com silagem de grãos úmidos de milho ou de sorgo.

Neste estudo os valores de rendimento de carcaça se enquadram na amplitude de valores citados na literatura, conforme publicado por Barbosa (1998), que destacou valor médio de $55 \%$ para rendimento de carcaça de bovinos abatidos com 24 meses de idade. Esses resultados 
concordam com os encontrados por Perotto et al. (2000), que verificaram rendimentos de carcaça de animais de vários cruzamentos entre 53,1 e 54,5\%. Valores superiores foram descritos por Passini et al. (2002) com animais jovens superprecoces F1 (Bos taurus e Bos indicus), com valores entre 57 e $58 \%$ de rendimento de carcaça.

Animais com mesma maturidade fisiológica, alimentados durante o mesmo período de confinamento e apresentando peso de carcaça e acabamento de gordura próximos, tendem a apresentar iguais rendimentos de carcaça, fato verificado neste trabalho nos grupos Canchim e nos cruzamentos. Diferenças no rendimento de carcaça são mais comumente relatadas quando os experimentos são conduzidos com animais de diferentes potenciais, os quais apresentam diferentes curvas de crescimento de tecidos, assim como diferentes pesos ao abate a mesma condição de acabamento, conforme relatado por Chambaz et al. (2003). De acordo com esses autores, animais de diferentes grupos raciais tiveram mesma alimentação e apresentaram valores semelhantes de espessura de gordura subcutânea, porém apresentaram pesos e rendimentos de carcaça diferentes.

Segundo Cervieri (2001), o peso ideal de abate para as condições brasileiras, considerando-se aspectos econômicos e de rendimento de cortes cárneos, situa-se entre 14 e 16 arrobas. Portanto, verifica-se que os pesos de carcaça dos quatro genótipos avaliados neste estudo, encontram-se na faixa considerada adequada para comercialização.

De acordo com Restle et al. (1999), o peso e o rendimento de carcaça são medidas de interesse dos frigoríficos para avaliação do valor do produto adquirido e dos custos operacionais, visto que carcaças com pesos diferentes demandam mesma mão-de-obra e mesmo tempo de processamento. Atualmente, o peso de carcaça é a forma de comercialização mais utilizada pelos frigoríficos.

Em relação ao rendimento dos principais cortes do traseiro, não houve diferença $(\mathrm{P}>0,05)$ entre os diferentes grupos raciais avaliados (Tabela 3), o que pode ser explicado pela similaridade dos pesos das carcaças dos mesmos, embora o peso do grupo Canchim tenha sido um pouco superior (Tabela 2).

A porcentagem do contrafilé na meia-carcaça do grupo Nelore foi inferior ao valor encontrado nos outros três grupos raciais avaliados (Tabela 4), o que poderia ser explicado pelo menor peso de carcaça e pela menor área de olho-de-lombo dos animais Nelore (longissimus dorsi) (Tabelas 3 e 2, respectivamente). Entretanto, o valor encontrado neste experimento para o grupo Nelore (Tabela 4) foi maior que o descrito por De Faria (2005), que relatou 7,12 e 7,74\% para dois grupos de Nelore, um grupo comum e um grupo de Nelore selecionado, respectivamente. Por outro lado, o valor de rendimento do contrafilé dos animais Nelore foi um pouco inferior ao publicado por Ledic et al (2000), de 10,83\%, obtido por meio de dados da pesagem de carcaças de 65.168 machos. Os valores encontrados para os outros grupos raciais estudados neste trabalho, são superiores aos valores descritos por Ledic et al. (2000), porém inferiores aos publicados por De Morais (1999) para animais de diferentes cruzamentos de raças europeias com Nelore (12,97 e 14,11\%).

A porcentagem de sebo foi maior nos animais Nelore (Tabela 3) e podem ser reflexo da precoce deposição de gordura nesta raça, denotada pela maior espessura de gordura subcutânea no momento do abate (Tabela 4). Isso pode estar relacionado a menor exigência de manutenção da raça Nelore, cerca de $10 \%$, em relação aos grupos taurinos, conforme descrito pelo NRC (1996), ou seja maior nível energético da ração proporciona resposta fisiológica com maior deposição de gordura na carcaça.

Os valores médios de área de ollho-de-lombo não apresentaram diferença significativa $(\mathrm{P}>0,05)$ entre os grupos raciais Canchim, TQ e CN, sendo que o grupo Nelore diferiu $(\mathrm{P}<0,05)$ apenas de Canchim e TQ (Tabela 4). Também não houve diferença estatística $(\mathrm{P}>0,05)$ para a espessura

Tabela 4 - Características de qualidade da carne de bovinos jovens pertencentes a diferentes grupos raciais

\begin{tabular}{|c|c|c|c|c|c|}
\hline \multirow[t]{2}{*}{ Variável } & \multicolumn{5}{|c|}{ Grupo racial } \\
\hline & Canchim & TQ & $\mathrm{CN}$ & Nelore & CV (\%) \\
\hline Área de olho-de-lombo $\left(\mathrm{cm}^{2}\right)$ & $91,30 \mathrm{a}$ & $84,60 a$ & $78,60 \mathrm{ab}$ & $67,90 b$ & 10,85 \\
\hline EGS (mm) & $5,00 \mathrm{ab}$ & $4,50 \mathrm{~b}$ & $5,10 \mathrm{ab}$ & $6,90 \mathrm{a}$ & 34,89 \\
\hline Marmorização & $2,00 \mathrm{a}$ & $2,00 \mathrm{a}$ & $1,70 \mathrm{a}$ & $2,10 \mathrm{a}$ & 22,61 \\
\hline Extrato etéreo (\%) & $1,99 a$ & $0,99 b$ & $1,44 \mathrm{ab}$ & $1,60 \mathrm{ab}$ & 48,79 \\
\hline Força cisalhamento 24 h (kg) & $2,48 b$ & $2,92 \mathrm{ab}$ & $3,81 \mathrm{a}$ & $2,69 b$ & 25,10 \\
\hline Força cisalhamento 7d maturação (kg) & $2,14 \mathrm{a}$ & $2,34 \mathrm{a}$ & $2,52 \mathrm{a}$ & $2,05 a$ & 20,11 \\
\hline PPC dia $0(g)$ & $24,41 \mathrm{ab}$ & $30,48 \mathrm{a}$ & $28,21 \mathrm{ab}$ & $17,84 b$ & 35,99 \\
\hline PPC dia 7 (g) & $30,19 a$ & $30,47 a$ & $28,33 a$ & $16,58 b$ & 33,37 \\
\hline
\end{tabular}

Médias seguidas por letras distintas na mesma linha, diferem $(\mathrm{p}<0,05)$ entre si pelo teste Tukey.

EGS: espessura de gordura subcutânea.

PPC: perdas por cocção. 
de gordura subcutânea entre os grupos raciais Canchim, TQ e CN. O grupo Nelore diferiu significativamente $(\mathrm{P}<0,05)$ do grupo TQ e não diferiu $(\mathrm{P}>0,05)$ dos grupos Canchim e CN (Tabela 4).

A área de olho-de-lombo em geral correlaciona-se diretamente com o peso da carcaça e com o rendimento de cortes comerciais do traseiro (Suguisawa et al., 2003). Neste estudo, os valores variaram de $91,3 \mathrm{~cm}^{2}$ para o Canchim puro a 67,9 cm² no Nelore, revelando coerência de rendimento do longissimus dorsi (contrafilé) e indicando que o Nelore apresentou valor significativamente inferior (10,22\%) à média geral de 11,45\% dos grupos com sangue Canchim (Tabela 3). Luchiari Filho \& Moura (1997) verificaram que tourinhos da raça Nelore com idade de 24 meses apresentaram valor médio de AOL igual a $67,18 \mathrm{~cm}^{2}$, valor menor que os encontrados nos animais mais jovens. Prado (2004), avaliando a AOL de animais de diferentes grupos raciais, publicaram valores médios de $63,29 \mathrm{~cm}^{2}$ para animais $1 / 2$ Canchim $\times$ Nelore e 53,16 $\mathrm{cm}^{2}$ para animais Nelore, inferiores aos obtidos neste trabalho. Felício (1997) relatou maior AOL em tourinhos da raça Nelore com idade de 24 meses $\left(72,14 \mathrm{~cm}^{2}\right)$ em relação ao encontrado neste trabalho. Restle et al. (1995) afirmaram que os valores médios de AOL apresentam alta correlação com o peso da carcaça. Segundo Chardulo (2000), comparando machos meiosangue Nelore com raças continentais e britânicas, verificaram que animais continentais tenderam a apresentar maiores AOL que animais mestiços britânicos abatidos no sistema superprecoce.

Os valores médios obtidos para AOL $\left(\mathrm{cm}^{2} / 100 \mathrm{~kg}\right.$ de carcaça) foram, respectivamente $31,33 \mathrm{~cm}^{2} / 100 \mathrm{~kg}$, $33,74 \mathrm{~cm}^{2} / 100 \mathrm{~kg}, 32,19 \mathrm{~cm}^{2} / 100 \mathrm{~kg}$ e $27,53 \mathrm{~cm}^{2} / 100 \mathrm{~kg}$ para os grupos raciais Canchim, TQ, CN e Nelore. O único valor inferior ao valor mínimo de $29 \mathrm{~cm}^{2} / 100 \mathrm{~kg}$, relatado por Luchiari Filho (2000), foi o do Nelore. Por outro lado, foi maior que os valores de $62,49 \mathrm{~cm}^{2}$ ou $24,07 \mathrm{~cm}^{2} / 100 \mathrm{~kg}$ encontrados por Manço (2006) para animais Nelore jovens.

Os valores de EGS para todos os grupos raciais (Tabela 4) foram maiores ou iguais a $4,5 \mathrm{~mm}$, o que os enquadra na categoria mediana. Somente o grupo Nelore apresentou valor maior que $6 \mathrm{~mm}$ para essa característica, o que o classifica na categoria uniforme. A EGS dos animais deste trabalho evitaria os possíveis danos causados na carcaça advindos do seu refrigeramento. A gordura subcutânea vem se tornando um importante indicador de qualidade, já que influencia a velocidade de refrigeramento da carcaça, comportando-se como um eficiente isolante térmico (Felicio, 1997). Desta forma, o valor mínimo de EGS exigido pelos frigoríficos nas especificações do programa de novilho superprecoce é de 3 a $10 \mathrm{~mm}$, valor que foi atingido pelos animais deste experimento.

Tanto o local de deposição como a quantidade de gordura depositada podem ser influenciados não só pelo fator genético como também pelo sistema de produção e pela alimentação fornecida. A deposição de tecido gorduroso representa alto custo dentro do processo produtivo e quando é acumulado nas regiões pélvica, renal e visceral, acarreta grandes perdas econômicas para o produtor.

A gordura de marmorização é a última a se depositar na carcaça durante a fase de crescimento do animal (Luchiari Filho, 2000), sendo consideravelmente influenciada pelo grupo racial. Neste trabalho, não foram observadas diferenças $(\mathrm{P}>0,05)$ entre o grau de marmorização avaliado com o olho nu, o que sugere que no sistema superprecoce os diferentes grupos raciais avaliados não apresentaram diferenças no que se refere ao fator genético.

A raça Canchim apresentou a maior porcentagem de extrato etéreo (Tabela 4) no músculo, comparada aos animais $\mathrm{TQ}$, porém não diferiu $(\mathrm{P}>0,05)$ dos outros grupos raciais, não havendo diferença $(P>0,05)$ entre os cruzamentos. Os valores médios observados para porcentagem de extrato etéreo no músculo longissimus dorsi nos respectivos grupos raciais Canchim, TQ, CN e Nelore (Tabela 4) são muito próximos aos encontrados por Manço (2002; 2006) em animais jovens de diferentes grupos raciais (1,22 e 1,34\%, respectivamente). Valores similares foram publicados por Felicio (1998), porém foram muito inferiores aos obtidos por Torres et al. (2000) de 2,78\%.

Diferenças no extrato etéreo do músculo longissimus dorsi podem estar também relacionadas ao método de amostragem e de extração de gordura. Uma pequena quantidade de gordura subcutânea remanescente na amostra do músculo pode resultar em valores mais altos para a quantidade de extrato etéreo. Uma padronização no preparo das amostras é necessária para evitar erros nos resultados (Manço, 2006). Neste estudo, foi realizada a análise de correlação dos valores de marmorização e teor de lipídeos na carne, demonstrando não haver correlação entre elas, provavelmente em razão da quantidade extraída por se tratar de animais com baixa aptidão genética para deposição de gordura.

Apesar de os valores médios de força de cisalhamento (FC) com 24 horas indicarem diferença $(\mathrm{P}<0,05)$ entre os animais $\mathrm{CN}$ em relação aos grupos Canchim e Nelore, não havendo esta diferença com os animais TQ, os intervalos dos valores revelam uma carne de padrão macia, uma vez que, segundo Koohmaraie et al. (1994), valores abaixo de 
4 kgf indicam carnes muito macias pela força de cisalhamento. Após sete dias de maturação, os valores de FC foram inferiores ao encontrados no dia 0 e não houve diferença significativa entre os genótipos avaliados. Os valores de força de cisalhamento observados neste trabalho foram menores que os registrados por Manço (2006) em animais da raça Nelore de 2 e 3 anos de idade (6,83 kg), mesmo após de 49 dias de maturação (4,83 kg). Independentemente de fatores como grupo racial, sistema de produção e idade de abate, a diminuição dos valores de força de cisalhamento ao longo do período de maturação é relatada por Hadlich, (2005).

Diferentes valores de força de cisalhamento são propostos por diferentes autores como limites entre a carne dura e macia: Shackelford et al. (1991) citaram 4,6 kg, Felicio (1999), 5 kg, Koohmaraie (1994), 6 kg, Johnson et al. (1990), 5,5 kg e Mackeith et al. (1985), 4,5 kg. Os animais produziram carne bastante macia, maturada ou não, possivelmente devido à idade jovem de abate dos animais e seu tipo de alimentação.

A perda de peso por cocção indica a capacidade de retenção de água da carne, de modo que o aumento dos valores de PPC indica diminuição da capacidade de retenção de água. Apesar de a carne do Nelore ter apresentado menor perda por cocção tanto no dia zero quanto aos sete dias de maturação, não foram significativas as perdas entre os tempos de maturação, quando submetidos à análise estatística para tempo ( $\mathrm{P}>0,05)$. De acordo com Bianchini et al. (2007) a proporção de água é maior em animais jovens, mas essa proporção diminui em músculos ricos em marmorização e com maior teor de gordura. Assim, a carne de animais com maior precocidade para deposição de gordura também tende a apresentar menores perdas totais que a carne de animais com menor precocidade para terminação. Uma possível explicação para a menor perda por cocção da carne de animais da raça Nelore (Tabela 4) poderia ser a quantidade de gordura na carne, embora não tenha havido diferença entre a marmorização e o teor de lipídeos da carne para todos os grupos genéticos.

\section{Conclusões}

Animais jovens oriundos de cruzamentos Canchim $\times$ Nelore podem ser utilizados com bons resultados na produção de bovinos no modelo biológico superprecoce, já que conciliam alto ganho de peso da raça Canchim com eficiente conversão alimentar dos animais Nelore. O grupo Nelore é adequado ao sistema de produção proposto e tem desempenho similar ao dos animais meiosangue Canchim $\times$ Nelore quanto ao ganho de peso, à conversão alimentar e ao melhor rendimento de carcaça.

\section{Literatura Citada}

BARBOSA, P.F. Cruzamentos industriais e a produção de novilhos precoces. In: SIMPÓSIO SOBRE PRODUÇAO INTENSIVA DE GADO DE CORTE, 1998, Campinas. Anais... Campinas: Colégio Brasileiro de Nutrição Animal, 1998. p.100-114.

BIANCHINI, W.; SILVEIRA, A.C.; JORGE, A.M. et al. Efeito do grupo genético sobre as características de carcaça e maciez da carne fresca e maturada de bovinos superprecoces. Revista Brasileira de Zootecnia, v.36, n.6, p.2109-2117, 2007 (supl.).

BLIGH, E.; DYER, W.J. A rapid method for total lipid extraction and purification. Canadian Journal of Biochemistry and Physiology, v.37, p.911-917, 1959.

CAPELLE, E.R.; VALADARES FILHO, S.C.; SILVA, J.F.C. et al. Estimativas do consumo e do ganho de peso de bovinos em condições brasileiras. Revista Brasileira de Zootecnia, v.30, n.6, p.1857-1865, 2001.

CERVIERI, R.C.; ARRIGONI, M.D.B.; OLIVEIRA, H.N. et al. Desempenho e características de carcaça de bezerros confinados recebendo dietas com diferentes degradabilidades da fração protéica. Revista Brasileira de Zootecnia, v.30, n.5, p.1590-1599, 2001.

CHAMBAZ, A.; DUFEY, P.A.; KREUZER, M. et al. Meat quality of Angus, Simmental, Charolais e Limousin steers compared at the same intramuscular fat content. Meat Science, v.63, p.491-500, 2003.

CHARDULO, L.A.L. Desempenho, níveis plasmáticos de hormônios, expressão e quantificação de proteínas musculares, características de carcaça e qualidade de carne de bovinos inteiros jovens de cinco diferentes grupos raciais submetidos a confinamento. 2000. 101f. Tese (Doutorado em Nutrição e Produção Animal) - Faculdade de Ciências Agronômicas e Veterinária, Jaboticabal, 2000.

COSTA, E.C.; RESTLE, J.; VAZ, F.N. et al. Desempenho de novilhos Red Angus superprecoces confinados e abatidos com diferentes pesos. Revista Brasileira de Zootecnia, v.31, n.1, p.129-138 2002.

CRUZ, G.M.; TULLIO, R.R.; ESTEVES, S.N. et al. Peso de abate de machos não-castrados para produção do bovino jovem. 2. Peso, idade e características da carcaça. Revista Brasileira de Zootecnia, v.33, n.3, p.646-657, 2004.

E FARIA, M.H.; ARRIGONI, M.D.B.; RESENDE, F.D. et al. Características físicas e químicas da carcaça de bovinos de diferentes grupos genéticos abatidos em três pontos de acabamento. In: REUNIÃO ANUAL DA SOCIEDADE BRASILEIRA DE ZOOTECNIA, 42., 2005, Goiânia. Anais... Goiânia: Sociedade Brasileira de Zootecnia, 2005. (CD-ROM).

DE MORAIS, J.P.G. Rendimento de cortes e características das fibras musculares de bovinos superprecoces, com aplicação de somatotropina bovina recombinante. 1999. 51f. Tese (Doutorado Nutrição e Produção Animal)-Faculdade de Medicina Veterinária e Zootecnia/Universidade Estadual Paulista, Botucatu, 1999.

EUCLIDES FILHO, K.; EUCLIDES, V.P.B.; FIGUEIREDO, G.R. et al. Efeito da suplementacao com concentrado sobre idade de abate e caracteristicas de carcaca de bovinos Nelore. Revista Brasileira de Zootecnia, v.26, n.6, p.1096-1102, 1997.

EUCLIDES FILHO K.; FATURI, C.; VAZ, F. et al. Desempenho de diferentes grupos raciais de bovinos de corte em confinamiento. Revista Brasileira de Zootecnia, v.32, n.5, p.1114-1122, 2003.

EUCLIDES FILHO K.; FATURI, C.; VAZ, F. et al. Eficiência bionutricional de animais mestiços de grupo raciais européias e Nelore. Revista Brasileira de Zootecnia, v.31, n.1, p.77-82, 2001.

FELÍCIO, P.E. Qualidade da carne bovina: características físicas e organolépticas. In: REUNIÃO ANUAL DA SOCIEDADE BRASILEIRA DE ZOOTECNIA, 36., 1999, Porto Alegre. Anais... Porto Alegre: Sociedade Brasileira de Zootecnia, 1999. (CD-ROM). 
FELÍCIO, P.E. Avaliação da qualidade de carne bovina. In: SIMPÓSIO SOBRE PRODUÇAO INTENSIVA DE GADO DE CORTE, 1998, Campinas. Anais... São Paulo: Colégio Brasileiro de Nutrição Animal, 1998. p.92-99.

FELÍCIO, P.E. Carne de touro jovem. Revista Nacional da Carne, n.243, p.91-92, 1997.

HADLICH, J.C.; MORALES, D.C.; CHARDULO, L.A.L. et al. Influência do genótipo Bos indicus nas características de qualidade da carne de bovinos superprecoces. In: CONGRESSO BRASILEIRO DE CIÊNCIA E TECNOLOGIA DE CARNES, 3.; CONGRESSO BRASILEIRO DE CIÊNCIA E TECNOLOGIA DE CARNES, 3., 2005, São Pedro. Anais... São Pedro: 2005. (CD-ROM).

IGARASI, M.S.; ARRIGONI, M.D.B.; SOUZA, A.A. et al. Desempenho de bovinos jovens alimentados com grão úmido de milho ou com grão úmido de sorgo. Revista Brasileira de Zootecnia, v.37, p.513-519, 2008 a.

IGARASI, M.S.; ARRIGONI, M.D.B.; HADLICH, J.C. et al. Características de carcaça e parâmetros de qualidade de carne de bovnios jovens alimentados com grão úmido de milho ou com grão úmido de sorgo. Revista Brasileira de Zootecnia, v.37, p.520-528, 2008b.

JOHNSON, D.D.; HUFFMAN, R.D. ; WILLIAMS, S.E. et al. Effect of percentage Brahman and Angus breeding age-season of feeding and slaughter end point on meat palatability and muscle characteristics. Journal of Animal Science, v.68, p.1980-1986, 1990 .

KOOHMARAiE, M. Muscle proteinases and meat aging. Meat Science, v.36, n.12, p.93-104, 1994.

KOOHMARAIE, M.; WHEELER, T.L.; SHACKELFORD, S.D. Beef tenderness: regulation and prediction. Reno: NCA Cattleman's College, 1994. p.1-25.

LEDIC, I.L.; TANHATI, H.; FERNANDES L.O. Rendimento integral de bovinos após abate. Ciências Agrotecnológicas, v.24, n.1, p.272-277, 2000.

LUChiari FILHO, A. Pecuária da carne bovina. 1.ed. São Paulo: Albino Luchiari Filho, 2000. 134p.

LUCHIARI FILHO, A.; MOURA, A.C. Situação atual e tendências da pecuária de corte no Brasil relacionados à qualidade de carne. In: SIMPÓSIO INTERNACIONAL SOBRE PRODUÇÃO INTENSIVA DE GADO DE CORTE, 1., 1997, São Paulo. Anais... São Paulo: Colégio Brasileiro de Nutrição Animal, 1997. p.42-44.

MANÇO, M.C.W.; ROÇA, R.O. Efeito da idade de abate em parâmetros qualitativos da carne de bovinos da raça Nelore. Boletim da Sociedade Brasileira de Ciência e Tecnologia de Alimentos, v.18, p.361-364, 2002

MANÇO M.C.W. Características físico-químicas, sensoriais e higiênicas da carne bovina em duas classes de maturidade e sob influência da maturação. 2006. 124f. Tese (Doutorado em Nutrição/Produção Animal) - Faculdade de Medicina Veterinária e Zootecnia/Universidade Estadual Paulista, Botucatu, 2006.

MACKEITH, F.K.; DEVOL, D.L.; MILES, R.S. et al. Chemical and sensory properties of thirteen major beef muscle. Journal of Animal Science, v.50, p.869-872, 1985.

NATIONAL RESEARCH COUNCIL - NRC. Nutrient requirements of beef cattle. 7.ed. Washington, D.C.: National Academy Press, 1996. 242p.

PACHECO, P.S.; DA SILVA, J.H.S.; RESTLE, J. et al. Desempenho de novilhos jovens e superjovens de diferentes grupos raciais em confinamento. Revista Brasileira de Zootecnia, v.34, n.5, p.1666-1667, 2005.

PASSINI, R. ; SILVEIRA, A.C.; TITTO, E.A.L. et al. Silagem de grãos úmidos de milho e de sorgo e níveis protéicos sobre desempenho e características da carcaça de novilhos superprecoces. Acta Scientiarum, v.24, n.4, p.1133-1140, 2002.

PEROTTO, D.; ABRAHÃO, J.J.S.; MOLETTA, J.L. Características quantitativas de carcaça de bovinos Zebu e de cruzamentos Bos Taurus x Zebu. Revista Brasileira de Zootecnia, v.29, n.6, p.20119-2029, 2000.

PRADO, C.S. Comparação de diferentes métodos de avaliação da área de olho de lombo e cobertura de gordura em bovinos de corte. Ciência Animal Brasileira, v.5, n.3, p.141-149, 2004.

RESTLE, J.; VAZ, F.N. Ganho de peso antes e após os sete meses no desenvolvimento e nas características de carcaça e carne de novilhos Charolês abatidos com dois anos. Revista Brasileira de Zootecnia, v.32, n.3, p.699-708, 2003.

RESTLE, J.; VAZ, F.N.; QUADROS, A.R.B. Características de carcaça e de carne de novilhos de diferentes genótipos de Hereford x Nelore. Revista Brasileira de Zootecnia, v.28, n.6, p.1245-1251, 1999.

RESTLE, J.; VAZ, F.N.; VAZ, R.Z. Qualidade de carcaça e da carne de novilhos de três grupos raciais abatidos aos quatorze meses de idade In: REUNIAO ANUAL DA SOCIEDADE BRASILEIRA DE ZOOTECNIA, 32., 1995, Brasília. Anais... Brasília: Sociedade Brasileira de Zootecnia, 1995. p.647-649.

SHACKELFORD, S.D.; WHEELER, T.L.; WHIPPLE, G. et al. An evaluation of tenderness of the longissimus muscle of Angus by Herdford versus Brahman crossbred heifers. Journal of Animal Science, v.69, p.171-177, 1991.

SILVEIRA, A.C. Sistema de produção de novilhos precoces. In: ENCONTRO NACIONAL SOBRE PRODUÇÃO DE NOVILHOS PRECOCES. 1., 1995, Campinas. Anais... Campinas: CATI, 1995. 56p.

SUGUISAWA, L.; MATTOS, W.R.S.; OLIVEIRA, H.N. et al. Ultrasonography as a predicting tool for carcass traits of young bulls. Scientia Agrícola, v.60, n.4, p.779-784, 2003.

TORRES, E.A.F.S.; CAMPOS, N.C.; CUARTE, M. et al. Composição centesimal e valor calórico de alimentos de origem animal. Ciência e Tecnologia de Alimentos, v.20, n.2, p.145-150, 2000. 